\title{
Perspectivas psicossociais para o estudo do cotidiano de trabalho ${ }^{1}$
}

\author{
Fábio de Oliveira* \\ Instituto de Psicologia, Universidade de São Paulo, São Paulo, SP, Brasil
}

Resumo: Este estudo teve por objetivo analisar o debate e o aprofundamento teórico e metodológico desenvolvido nos estudos sobre a vida cotidiana no trabalho. A investigação partiu do diálogo interdisciplinar entre a antropologia do trabalho, a ergologia e a psicologia social do trabalho e sistematizou as contribuições mútuas entre esses campos científicos, suas aproximações e seus afastamentos da tematização e da apropriação da atividade humana no trabalho sob a perspectiva do cotidiano. A análise comparativa destacou eixos que diferenciam as formas de aproximação ao objeto, que se referem às relações estabelecidas entre saberes práticos e técnico-científicos e aos modos de intervenção sobre as situações de trabalho. As abordagens comparativas compartilham o interesse em conhecer o trabalho real, o valor conferido aos conhecimentos dos trabalhadores e a sensibilidade às dimensões micropolíticas do cotidiano. Conclui-se que a localização em cada um desses eixos depende da maior ou menor filiação às tradições da antropologia ou da ergonomia.

Palavras-chave: Psicologia social do trabalho, ergologia, antropologia do trabalho, cotidiano, micropolítica.

\section{Introdução}

Considerando, por um lado, a constatação de semelhanças consideráveis entre algumas abordagens do trabalho e, de outro, o vislumbre das possíveis contribuições dos estudos sobre o cotidiano para seu desenvolvimento, a presente investigação buscou comparar três dessas abordagens - antropologia do trabalho, ergologia e psicologia social do trabalho -, por meio da sistematização de suas contribuições mútuas, buscando situar os estudos do trabalho no debate mais amplo sobre cotidiano e sociedade e tendo como guia a interrogação sobre como o cotidiano figura em cada uma das três perspectivas na apreensão de situações concretas de trabalho.

Partimos de nossa própria disciplina de origem, a psicologia social do trabalho, e do interesse pelo cotidiano como perspectiva para a compreensão do trabalho humano (Sato, Andrada, Évora, Neves, \& Oliveira, 2011; Sato, Bernardo, \& Oliveira, 2008; Sato \& Oliveira, 2008) e buscamos saber como outras disciplinas dedicadas ao estudo do trabalho tematizam o cotidiano ao debruçarem-se sobre seu objeto.

\section{Antropologia do trabalho}

A antropologia volta-se para o estudo do trabalho nas sociedades ocidentais industrializadas valendo-se es-

1 O artigo reúne resultados da pesquisa de pós-doutoramento desenvolvida no Instituto de Ciências Sociais da Universidade de Lisboa em 2012, sob a supervisão de Paulo Granjo. Agradecimentos à FAPESP (Bolsa de Pesquisa no Exterior, processo n ${ }^{\circ} 2011 / 11627$ 9) e aos colegas do grupo de estudos sobre cotidiano e trabalho do IPUSP, especialmente a Leny Sato e Maria Chalfin Coutinho.

* E-mail: fabioliv@usp.br pecialmente da tradição etnográfica e de suas contribuições para a compreensão da técnica e da cultura.

Uma questão que já de início foi imposta a essa empreitada dizia respeito à legitimidade de uma antropologia feita "à porta de casa" (Granjo, 2004, p. 295), isto é, quando o objeto de estudo do antropólogo é a própria sociedade à qual ele pertence. Embora essa seja uma questão datada e uma antropologia urbana, para citar um exemplo, já tenha tomado corpo há muito tempo (Magnani \& Torres, 1996), o breve comentário sobre essa questão pode ajudar a entender a visada da antropologia.

Na perspectiva tradicionalista, a distância social entre observador e objeto seria a "instância viabilizadora da legibilidade deste último" (Granjo, 2004, p. 301). Assim, o olhar para além das aparências seria garantido pelo espírito crítico e pela "exterioridade" do observador "e sua consequente necessidade de construir uma coerência daquilo que observa, sem ser 'tolhido' pelos pressupostos e referentes culturais partilhados pelo grupo observado - que à partida desconhece e que nunca chegarão a ser os seus" (p. 301). A condição de antropólogo "forasteiro" forneceria "através das mutações que ele próprio sofre, a chave para a compreensão da 'sociedade' que observa” (p. 302).

Classificando essa visão como "heroica e iniciática", Granjo (2004) questiona (recorrendo aos argumentos de José Cutileiro, 1973) seus pressupostos afirmando o caráter cultural ambíguo do antropólogo:

Por outras palavras, o antropólogo já não é stricto sensu um autóctone, pois as suas experiências e referentes culturais são filtrados, na sua percepção e conceptualização, por um segundo sistema de referências, concebido 
para reflectir acerca deles - que é o da sua disciplina, na qual foi também socializado. Completando o raciocínio, a sua sociedade não é um quadro de referências quase naturalizado, mas um ambiente social permanentemente olhado de forma reflexiva, tal como os antropólogos profissionalmente a olham. (p. 304)

Mais do que isso, a possibilidade de uma antropologia da sociedade em que vive o pesquisador e do trabalho que acontece nessa sociedade, na tensão entre proximidade e diferença, está na constatação de que a homogeneidade cultural não é um fenômeno que se observa nos Estados nacionais nem tampouco nos contextos urbanos. $\mathrm{O}$ antropólogo que entra em uma fábrica, afinal, é em grande medida um estranho. E, mesmo o operário que se ressocializa com o antropólogo, muito provavelmente já não verá o contexto da fábrica do mesmo modo como o fazia antes.

O problema talvez venha a ser outro então: "a falsa sensação de familiaridade com o objecto, em resultado da já referida semelhança de referentes e pressupostos relacionais, situacionais e técnicos" (p. 307). Ora, na medida em que o trabalho humano parece-nos familiar, faz necessária "uma construção da distância":

Ou seja, a compreensão das práticas e processos que observamos num contexto industrial exige-nos uma permanente atenção à diferença e especificidade desse objecto aparentemente tão familiar e transparente, uma abordagem qualitativa que supere desconfianças e tentativas de instrumentalização (permitindo ultrapassar o discurso produzido para o exterior) e ponha em causa os pressupostos comuns, sob pena da sua mera reprodução superficial. Uma reprodução que tornaria a investigação socialmente inútil - porque teoricamente irrelevante e vazia de ensinamentos novos que ultrapassem o quadro dos pressupostos que moldam a gestão da realidade que se pretenda compreender e eventualmente melhorar. (Granjo, 2004, p. 308)

Essas preocupações, entre tantas outras, que mobilizaram o debate entre antropólogos, evidenciam um aspecto importante da investigação nesse campo: o respeito à alteridade e o esforço para evitar que as culturas ou os grupos estudados sejam interpretados a partir dos referenciais do próprio pesquisador.

Bouvier $(1989,1991)$ aponta a insuficiência da sociologia tradicional para a análise do trabalho e propõe o aporte da socioantropologia do trabalho, que se origina da articulação entre as duas disciplinas. $\mathrm{O}$ autor afirma que as "ciências sociais, e em particular a sociologia do trabalho, tendem principalmente a analisar as disfunções ou a estudar a divisão de tarefas" (Bouvier, 1990, p. 132), o que lhe parece insuficiente:

Aos resultados dos enfoques anteriores não se unirá uma análise sequencial de tal ou qual variável do trabalho taylorista-fordista... é preciso recorrer aos hábitos e às representações polissêmicas dos hábitos. A análise das cotidianidades e de seus componentes deve permitir captar o melhor possível a essência mesma dos atos do trabalho contemporâneo. Aos instrumentos da sociologia clássica do trabalho, ... convém associar certos conceitos e métodos provenientes de outros horizontes disciplinares.... Para captar com um enfoque novo a constituição de hábitos e de complexidades do trabalho moderno, a entrada de conceitos e de métodos antropológicos se revela frutífera, já que [a antropologia] pretende estudar o trabalho apenas em sua realização localizada, o que significa estudar sua polissemia e não de analisar suas variáveis. (p. 133)

Segundo o autor, a socioantropologia prioriza a dimensão simbólica e intersubjetiva do trabalho (rituais, atitudes, representações, tradições de diferentes ofícios, sociabilidades no/do trabalho). Para isso, o antropólogo prolonga sua permanência no campo para "tentar encontrar e compreender tanto os suportes simbólicos dos usos e dos valores usuais dos meios de trabalho escolhidos, como a totalidade do fato social" (p. 135).

A inserção demorada no campo e o olhar para os pequenos acontecimentos cotidianos permitem lançar luz sobre aspectos sutis da atividade, como os erros latentes dos sistemas, as estratégias para contorná-los e a construção de saberes práticos coletivos. Esses elementos comparecem, por exemplo, ao registro etnográfico da produção automática de vidro, feito por Marques (2009) em seu trabalho de campo na indústria portuguesa de garrafas:

Automática, esta não é, contudo, auto-regulada. $\mathrm{Na}$ complexidade de seu funcionamento e da sua relação com a matéria-prima, frequentemente emergem erros ou ineficiências, cuja acumulação é susceptível de comprometer o fabrico - levando, designadamente, à ocorrência de defeitos no produto e à baixa do rendimento da máquina. Corrigir ou compensar esses erros, mantendo a operação nos parâmetros considerados correctos, eis no que consiste a condução da máquina.... Neste processo ... assume também o maior relevo um significativo corpus de conhecimento técnico e social construído pelos condutores sobre a máquina, o vidro, a organização, o trabalho... - conhecimento que é endógeno, relacional e reservado. (p. 202)

A realização desses ajustes e a busca por "manter a autonomia e a qualificação do seu trabalho, recusar o papel de robots humanos (a expressão é local), de meros apêndices da máquina, implica, por parte dos condutores, quotidianas transgressão e resistência" (p. 203), ao que os gestores respondem ambiguamente, pois essas ações favorecem parcialmente os objetivos da empresa. Afirma a autora ainda que: "Em qualquer das situações encontrámos activas estratégias operárias para manter o controlo do trabalho que o dispositivo técnico-organizacional tendia a retirar-lhes" (p. 204). 
A autora deixa claro, portanto, que a etnografia fabril, a observação direta dos locais de trabalho, é a principal marca e contribuição da antropologia para os estudos do trabalho, quando se busca o conhecimento do mundo concreto e vivido (Marques, 2009, p. 193).

\section{Ergologia}

Ao narrar a história da ergologia, Schwartz (2000a) destaca a influência de Ivar Oddone (1984). As contribuições de Oddone e sua equipe (Oddone, 1984; Oddone, Re, \& Briante, 1981) marcam uma inversão nas formas de produzir conhecimento e de conduzir intervenções nos ambientes de trabalho, na medida em que reposicionam os saberes práticos dos trabalhadores na sua relação com os saberes técnico-acadêmicos. Essa inversão desdobra-se no conceito de "comunidade científica ampliada", que se refere aos espaços construídos por pesquisadores e trabalhadores, nos quais confrontam seus diferentes saberes com o objetivo de analisar o trabalho e propor sua transformação, dentro do espírito da não-delegação aos especialistas (Oddone et al., 1986).

Schwartz e seus colegas, a partir do início da década 1980, organizaram atividades de formação orientadas por esse conceito. As primeiras experiências (Schwartz \& Faïta, 1985) levaram à proposição de um curso denominado Análise Pluridisciplinar das Situações de Trabalho (APST), que buscou articular pesquisadores e trabalhadores em torno do enfrentamento dos desafios impostos pelas estratégias de racionalização do trabalho em um momento de questionamento do taylorismo-fordismo e de efetivar o encontro entre saberes teóricos (modelos conceituais relativamente mais estáveis no tempo) e saberes práticos ligados à experiência dos trabalhadores (Schwartz, 2000a).

A partir das comunidades científicas ampliadas, Schwartz (2000a) propôs o que chamou de Dispositivo Dinâmico a Três Polos para a análise da atividade de trabalho. Esses três polos seriam: os conceitos, os saberes gerados na prática e as exigências ético-epistemológicas.

Sobre o polo dos conceitos, pode-se dizer que ele comporta:

materiais para o conhecimento, por exemplo, sobre a distinção entre atividade prescrita e real, sobre a noção de mercado, sobre o corpo humano, sobre as práticas linguísticas, sobre a comunicação e as dificuldades de traduzir em palavras. (p. 44)

Os conceitos, formais e mais abstratos, relacionam-se com o polo dos saberes gerados na atividade, isto é, com os saberes locais construídos a partir do enfrentamento cotidiano com os meios de trabalho.

O terceiro polo sugerido por Schwartz (2000a), que se relaciona com os dois primeiros, denomina-se polo das exigências éticas e epistemológicas:

O terceiro polo, contrariamente aos dois outros, não contém saberes pré-estocados ou saberes investidos nas ati- vidades, mas impõe, de uma parte, uma certa humildade dos universitários para retornar a palavra à atividade e, de outra parte, uma aceitação da disciplina do conceito e de sua aprendizagem pelos protagonistas das atividade. (p. 44)

Nota-se, na proposição desse dispositivo, o reconhecimento do valor do conhecimento dos trabalhadores, 0 compromisso com a transformação do trabalho e um lugar para o conhecimento técnico-científico sobre o trabalho trazido pelos pesquisadores.

Esses elementos devem ser compreendidos a partir do conjunto das influências que contribuíram para a configuração da abordagem ergológica, dentre elas a ergonomia da atividade (Daniellou, 2004; Guérin, Laville, Durafforug, \& Kerguelen, 2001). Conhecer o trabalho para modificá-lo e adequá-lo às pessoas que trabalham é o objetivo da ergonomia, o que coloca a intervenção ou o diagnóstico com vistas à intervenção como elementos centrais dessa abordagem. A ergonomia, em suas diferentes versões, construiu uma série de conhecimentos que visam a atingir esse objetivo. Por sua vez, a ergonomia da atividade avança em relação à ergonomia tradicional justamente por abrir espaço para os conhecimentos práticos dos trabalhadores.

A aproximação da ergonomia da atividade ao fazer do trabalho não se realiza apenas com o objetivo de conhecer esse outro que são os trabalhadores, suas formas de pensar a realidade, suas produções materiais e simbólicas, seus modos de sociabilidade, mas busca aproximar os saberes práticos dos trabalhadores dos saberes técnico-científicos dos profissionais da ergonomia, que têm o que dizer sobre a adaptação do trabalho ao ser humano.

Além desse legado, a ergologia também herda da ergonomia da atividade o interesse pelo trabalho concreto. Nela, isso toma forma a partir da constatação da existência de uma distância variável entre o que é planejado e o que efetivamente é realizado. Isso levou à formulação dos conceitos de trabalho prescrito e trabalho real. Telles e Alvarez (2004) esclarecem esse ponto:

Ao se aproximar de seu objeto - o trabalho humano em situações reais, a ergonomia mostrou que o trabalho efetuado não corresponde jamais ao trabalho esperado, fixado por regras, orientado por objetivos determinados, segundo representações das condições de realização. Ao realizar a tarefa, a pessoa se encontra diante de diversas fontes de variabilidades: a do sistema técnico e organizacional (panes, disfuncionamentos, dificuldades de previsão), a sua própria variabilidade e a dos outros (fadiga, ritmicidade circadiana, efeitos da idade, experiência), e a do(s) coletivo(s) de trabalho pertinente(s).... A atividade de trabalho consiste na realização do trabalho prescrito, considerando-se as restrições e as vantagens dispostas pelas variabilidades ..., servindo-se [as pessoas] dos meios disponíveis ou inventando outros meios. (p. 71)

Segundo Schwartz (2000b), a presença viva do indivíduo é convocada no trabalho, na medida em que as for- 
mas de lidar com as variabilidades referidas acima, por não estarem prescritas de antemão, exigem um tipo de resposta que não se limita à mera execução de ordens e lançam o indivíduo em um debate sobre os modos de fazer: "Assim, no interior das coerções materiais e sociais e trabalhando-as, abre-se o espaço para uma gestão diferenciada de si mesmo" (p. 37).

As prescrições não se materializam sozinhas, elas passam pelo trabalhador, ou seja, é pelo trabalhador que elas operam. É nesse sentido que o autor propõe que não há mera execução na realização de uma atividade de trabalho, mas um tipo de uso que o trabalhador faz de si mesmo, de suas capacidades, para além da simplicidade aparente do trabalho. Há usos possíveis, negociações entre esses possíveis e resistências mediadas por valores sociais, de classe, profissionais que se atualizam na atividade de trabalho.

Esse uso de si constitui-se como uma tensão problemática, ao envolver a negociação entre possíveis:

É o indivíduo no seu ser que é convocado; são, mesmo no inaparente, recursos e capacidades infinitamente mais vastos que os que são explicitados, que a tarefa requer, mesmo que esse apelo possa ser globalmente esterilizante em relação às virtualidades individuais. (Schwartz, 2000b, p. 41)

O uso de si implica ao mesmo tempo um "recentramento do meio em torno de possíveis singulares do sujeito, recomposição, mesmo no ínfimo, de um mundo à sua conveniência" (Schwartz, 2000b, p. 44), isto é, reconhece-se o esforço, mesmo que nem sempre bem sucedido, de reconfiguração das normas diante das variabilidades do meio de trabalho. Nesse sentido, Silva (2008) afirma:

O meio de trabalho é reconfigurado pelo trabalhador; há sempre um recanto, mesmo pequeno, onde se encontram traços de identidade dos operários: a disposição das ferramentas, a limpeza, uma mensagem, uma flor. O operário apropria-se, na medida do possível, dos espaços de trabalho para torná-los mais adaptados a si mesmo, nem sempre para facilitar diretamente a rentabilidade produtiva. (p. 118)

A renormalização preenche os espaços vazios deixados pelas normas, revelando modos próprios de fazer a atividade apoiados na experiência sedimentada dos coletivos de trabalho. "Manhas", "macetes", "jeitinhos", "gambiarras" são expressões que denunciam a presença desses modos compartilhados de fazer.

\section{Psicologia social do trabalho}

A psicologia social do trabalho - que parte de perspectivas críticas, geralmente situadas no espaço existente entre as matrizes compreensiva e dialética das ciências sociais -, ao delimitar o trabalho como objeto, constrói este não como um problema de gestão (caminho que, em ge- ral, assume um caráter instrumental), mas um fenômeno psicossocial (Spink, 1996). Assim, apresenta-se, em parte, como um "retorno" à psicologia social, na medida em que deixa de recorrer, como é comum na psicologia feita em empresas, a conceitos construídos no campo epistemológico da administração (Rodrigues, 1999).

Deve-se considerar ainda que há várias abordagens psicossociais do trabalho que assumem nomenclaturas outras, embora sejam comuns as convergências teóricas e metodológicas com o que se tenta delimitar pelo rótulo "psicologia social do trabalho". Do mesmo modo, convergências também são identificadas nas fronteiras com alguns campos interdisciplinares de estudo do trabalho, como as "clínicas do trabalho" (Lhuilier, 2006, 2011), das quais a ergologia (Schwartz, 2000a) e a clínica da atividade (Clot, 2006) são alguns exemplos.

No contexto brasileiro, a designação "psicologia social do trabalho" é formulada a partir dos desenvolvimentos do campo interdisciplinar da saúde dos trabalhadores e de um esforço de diferenciação em relação às práticas de psicólogos de empresas e ao arcabouço teórico da psicologia organizacional (Sato, 2010).

Trata-se de uma denominação recente, embora estudos psicossociais sobre o trabalho tenham uma história relativamente longa em nosso contexto, como aponta Sato (2010):

A segunda vertente toma o mundo do trabalho como foco de estudos e problematização, não tendo como preocupação inicial construir e delimitar um espaço de aplicação. Informada pela Psicologia Social, aqui importam os problemas sociais e humanos no trabalho, presentes nos espaços organizacionais e fora dele. Interessa compreender fenômenos como: identidade, processos de interação social, processos de percepção e de cognição social e a subjetividade. ... Muito embora essa vertente esteja há muito presente, temos a hipótese de que não tenham sido consideradas como uma perspectiva da Psicologia do Trabalho e das Organizações porque fogem a uma determinada concepção sobre a formação e a profissionalização em Psicologia, uma vez que é forte entre nós a dicotomia entre conteúdos e abordagens profissionalizantes e não profissionalizantes, cabendo àqueles apresentar modos e técnicas para intervir na realidade. Desta forma, muitos estudos e pesquisas que tomam o trabalho e os processos organizativos focalizando aqueles fenômenos (identidade, subjetividade etc.) têm sido categorizadas sob a denominação genérica de Psicologia Social. (Sato, 2010, p. 43)

No caminho da construção de uma perspectiva em psicologia social do trabalho, Spink (1996) propõe como unidade de análise "o processo organizativo enquanto fluxo de ações e significados sociais" (p. 176). Sugere ainda uma aproximação à psicologia social sociológica como forma de lidar de modo mais consistente com a relação entre indivíduos e sociedade: 
O resultado tem sido um avanço significativo da capacidade de compreender os eventos do dia-a-dia como uma prática intersubjetiva e socialmente relevante, base da produção e reprodução de processos sociais. Começou-se a desfazer a noção, implícita na falsa separação do indivíduo e contexto, de que o empírico tem [teria] dois níveis - um nível psicológico e um nível sociológico. (p. 177).

Essa perspectiva psicossocial para o estudo do trabalho, ecoando as influências de Oddone (Oddone et al., 1981), confere grande importância à perspectiva dos trabalhadores e às ações que se desenvolvem do dia a dia de trabalho:

A perspectiva da Psicologia Social convida-nos a olhar o trabalho e os processos organizativos a partir do ponto de vista dos trabalhadores, mostrando situações difíceis de ser vividas, estratégias e táticas criadas e utilizadas para com elas lidar. (Sato, 2010, p. 44)

Essas dimensões, deve-se dizer, foram deixadas de lado pelas abordagens tradicionais da psicologia ao trabalho:

O "chão de fábrica" apresenta-se como um espaço de emergência de grandes questões para a Psicologia, na medida em que possibilita revisitar, a partir do enfoque da Saúde e da Psicologia Social, um universo que fora ignorado pela Psicologia e que, para Oddone e cols. (1981, p. 23) constitui uma "Psicologia do Trabalho não escrita”. (Sato, 2010, p. 46)

Ao fazerem um balanço dos estudos em psicologia social do trabalho, Sato, Bernardo e Oliveira (2008) reconhecem nessa abordagem da atividade humana um olhar para os acontecimentos cotidianos e a tensão entre as realidades concretas de trabalho e as estratégias cotidianas dos trabalhadores para fazer frente a elas:

Esses estudos apontam para a tensão entre as realidades de trabalho e a engenhosidade cotidiana necessária, de que lançam mão os trabalhadores, para fazer o trabalho acontecer. Essas realidades de trabalho aparecem para os trabalhadores por meio da articulação de variados elementos: as condições materiais, a maior ou menor assimetria das relações de poder, as possibilidades de agir autonomamente, os sentidos do trabalho.

O que remete diretamente à compreensão do cotidiano de trabalho proposta por Peter Spink (1996) a partir de sua leitura dos campos de investigação abertos por autores como G. H. Mead, K. Lewin e H. Garfinkel:

Desde os trabalhos pioneiros dos interacionistas simbólicos dentro da linha aberta por G. H. Mead, e dos pesquisadores de campo lewinianos (por exemplo, Barker e Wright), até as propostas etnometodológicas, e também o debate crítico dentro da antropologia da ação ou da semiótica, torna-se cada vez mais claro que o dia-a-dia, o cotidiano mundano, não é um vazio de restos aleatoriamente espalhados pelo chão mas, ao contrário, é o lugar onde a gente se reconhece como gente no sentido comunicativo. Reconhece-se também que a capacidade de ordenar atividades e ações, de criar diferentes e novas formas de agir é uma característica essencialmente humana e que é esta a base que materializa os passos da humanidade no horizonte reconhecível do dia-a-dia, mesmo que os passos sejam contraditórios e seus significados confusos.... O dia-a-dia organizacional é onde se trabalha; parte esta cujo horizonte - ou limite - é sociotecnicamente configurado (pelo espaço físico, maquinaria, tarefas, horários, pressupostos de controle e práticas de interação). Nesta concepção, a ordem organizacional tem muito mais a ver com uma ordem negociada entre cotidianos distintos - departamentos, áreas, salas de aula, repartições e lojas - e o todo é muito mais um residual, sem nenhuma característica homogênea. Nesta ótica, as organizações enquanto coisas reificadas como "algo" nada mais são do que a sombra projetada pelo cotidiano em movimento ou, talvez melhor, as pegadas deixadas pela passagem da ação enquanto atividade humana. A sombra inibe e a pegada convida, porém ambas são as consequências da ação e não sua origem. (p. 186)

\section{Interfaces entre as abordagens}

Embora, do ponto de vista formal, sejam tradições diferentes, as abordagens em questão apresentam sobreposições, influências mútuas e filiações em comum.

A antropologia, por exemplo, deixou um legado considerável à psicologia social e à ergologia. Não só no que diz respeito à etnografia e a toda a discussão metodológica que suscita, mas no que se refere também às formas de compreender a cultura e a alteridade.

Pelo caminho que tem construído no contexto brasileiro, a psicologia social do trabalho estabeleceu interfaces com a antropologia e as demais ciências sociais. São notáveis, por exemplo, as interlocuções com Geertz (Andrada, 2010) e Certeau (Sato \& Oliveira, 2008), para ficarmos em apenas dois exemplos.

Do mesmo modo, a ergologia tem sua dívida com a antropologia, como demonstram as referências de Schwartz (2011) aos estudos de Leroi-Gourhan (1945) como sendo um dos pontos de partida da abordagem ergológica, ao lado de Oddone (1984), de Canguilhem (1947) e da ergonomia da atividade.

Além da antropologia, outra disciplina que merece destaque pela influência que exerceu sobre o campo de estudos do trabalho é a ergonomia. Seu legado faz-se sentir sobretudo na ergologia e na psicologia social, mas é de chamar a atenção, por exemplo, que os conceitos de "trabalho prescrito" e "trabalho real", popularizados por Ombredane e Faverge (1955), mesmo que tenham passado por desenvolvimentos posteriores nas mãos de diversos 
outros autores, estejam presentes em muitos estudos sobre o trabalho humano (Teiger, 1993), incluindo a antropologia do trabalho (Durão \& Marques, 2001, p. 58).

Sobre o lugar da ergonomia, ao salientar sua capacidade para iluminar dimensões invisíveis do trabalho, Schwartz (2011) afirma:

Isso não quer dizer que a ergonomia seja o alfa e o ômega de uma abordagem "sensata" do trabalho. Ao contrário, podemos ser persuadidos de alguns de seus limites.... A ergonomia é múltipla, mas, por vezes limitada, pois ela não se apropria sempre dos desafios que fez emergir. Mas sem a aprendizagem do olhar sobre o trabalho para a qual instrui a ergonomia, não há muitas chances de mensurar a importância de uma assunção das dimensões invisíveis ou "em penumbra" do trabalho. O que o ergonomista denomina de "crônica da atividade" revela a verdadeira densidade da atividade industriosa: esta jamais é puro encadeamento de normas, de procedimentos, pensados anteriormente e sem a pessoa que vai trabalhar, porque isso é simplesmente impossível e ao mesmo tempo muito difícil de ser vivido. (p. 33)

Antropologia e ergonomia apresentam-se como polos de um eixo central que, como fomos capazes de apreender, organiza as abordagens sobre as quais nos debruçamos neste estudo e introduz nuances nos modos de compreensão do cotidiano de trabalho, especialmente no que se refere às formas de aproximação ao objeto, seja nas relações estabelecidas entre saberes práticos e técnico-científicos, seja nos modos de intervenção sobre as situações de trabalho.

Assim, um segundo eixo derivado do primeiro diz respeito às diferenças entre a postura antropológica, de conhecer o trabalho tal como ele é e com a menor intervenção possível do observador, e a postura do ergonomista da atividade, de assumir os conhecimentos dos trabalhadores como prioritários e centrais, mas de considerar que os conhecimentos técnico-científicos que detém devem se somar aos primeiros.

Note-se que a ergonomia, embora priorize os saberes operários, por constituir-se como uma ciência ou arte da intervenção sobre o trabalho e como um campo interdisciplinar que conta, entre outros, com engenheiros e técnicos de segurança, priorizou em seu processo de desenvolvimento o diálogo entre saberes locais e saberes técnico-científicos. E isso aparece de forma amadurecida na abordagem ergológica em sua proposição de um "dispositivo dinâmico de três polos", como foi visto acima.

As três abordagens analisadas compartilham um profundo respeito pelo conhecimento dos trabalhadores e atribuem a ele um papel fundamental na tarefa de compreender o trabalho. Porém é possível reconhecer em alguns momentos que, tanto os estudos antropológicos quanto a vertente da psicologia social do trabalho que destacamos neste texto, assumem uma postura diante de seu objeto que aprendemos com a própria antropologia: vai-se a campo mais para saber o que pensam os trabalhadores sobre seu trabalho do que como detentores de algum saber sobre esse trabalho.
Essas diferenças refletem-se nas configurações das metodologias de pesquisa e de intervenção, o que compreendemos como um terceiro eixo diferenciador, que se revela nas tensões entre os objetivos de conhecer a complexidade do trabalho e o de transformá-lo. Isso não quer dizer que sejam objetivos opostos ou que conhecer o trabalho não forneça elementos para sua transformação ou, ainda, que a transformação não pressuponha conhecer o que se quer transformar. $\mathrm{O}$ fato é que o antropólogo do trabalho, como vimos acima, conduz sua ação mais como o etnólogo que se aproxima de outra sociedade do que como o engenheiro de segurança que tem o que dizer sobre a proteção de máquinas.

O compromisso com a mudança do trabalho contém um risco, se não inserido em uma dimensão temporal: se apenas são buscadas as mudanças a curto prazo, o par investigador-trabalhador submete-se ao possível, ao "razoável", e perde-se o horizonte das mudanças mais profundas ou a consciência da constante contradição que subjaz as relações de trabalho em nossas sociedades.

Para todos os propósitos, entretanto, compreendemos que a questão coloca-se sobre a perspectiva da intervenção ser direta ou indireta, tendo em vista que o horizonte das abordagens analisadas é emancipatório.

Outra nuance explicitada especialmente pela ergologia é a percepção da existência de uma certa "opacidade inerente a toda experiência" (Athayde \& Brito, 2011, p. 267), de modo que não se pode "ter no protagonista da atividade um fiel informante, portador da verdade sobre o que faz" (p. 167), tendo em vista que a experiência não está lá pronta para ser comunicada, o que exige do trabalho de pesquisa $o$ diálogo ativo entre pesquisadores e trabalhadores.

As abordagens do trabalho no campo da psicologia social percorrem esses três eixos, localizando-se em diferentes pontos de distância e proximidade em relação aos polos correspondentes.

Apesar das diferenças apresentadas, a compreensão de que o trabalho é um mundo a conhecer, em alguma medida velado e enigmático, é compartilhada pelas abordagens que são objeto da presente comparação. Do mesmo modo, é-lhes comum a compreensão de que o trabalho é espaço de produção intersubjetiva, no qual o simbólico faz a mediação entre pessoas e meio técnico; por isso, o foco nos processos construtivos, isto é, naquilo que se produz em termos simbólicos (saberes coletivos, micropolítica) e materiais investidos simbolicamente (técnicas, formas de enfrentamento da realidade).

Seja pela influência da etnografia (e seu instrumental para conhecer realidades culturais diversas), seja pela influência da ergonomia da atividade (e sua consciência da distância entre trabalho real e trabalho prescrito), as três abordagens privilegiam os dados de campo, na medida em que compartilham o "primado do terreno", isto é, suspeitam dos estudos demasiadamente guiados por teorias e das abordagens por demais generalizantes, conferindo à teoria um lugar de ferramenta a ser aperfeiçoada no confronto com o objeto (Becker, 1999). 
O primado do campo é acompanhado de críticas a concepções correntes sobre o trabalho, que o simplificam e que refletem concepções ideologicamente marcadas a seu respeito. Há grande convergência na constatação da opacidade do trabalho real para os gestores, por exemplo. Conforme Granjo (1998):

A experiência de terreno [campo] rapidamente revela três aspectos de particular importância: em primeiro lugar, até que ponto são plurais e intrincados os mecanismos em cujo quadro se concretiza a vivência e eficácia do trabalho industrial e em que medida eles são desconhecidos por quem tem poder de decisão; em segundo lugar, até que ponto são marcadas as barreiras de percepção e comunicação entre diferentes grupos socioprofissionais ali envolvidos e de que modo os pressupostos tecnocráticos e de gestão podem chocar com as condições que enquadram a vida laboral; por fim, até que ponto a distância cognitiva entre o contexto laboral e quem decide e gere, o desconhecimento e o inquestionamento, podem fazer com que opções aparentemente lógicas, à luz dos pressupostos de que decorrem, venham a ter efeitos perversos quer sobre a vida dos trabalhadores, quer sobre os objectivos económicos que as originaram. (p. 76)

\section{Cotidiano e trabalho real}

O trabalho é certamente espaço de reprodução social, mas, seguindo Lefebvre (1991), é também espaço da reprodução das contradições sociais. O cotidiano de trabalho embora comporte a repetição (representada pelas prescrições, pelas normas antecedentes), é povoado por práticas que não foram previamente concebidas. A repetição estrutura o cotidiano. "As rotinas nos liberam do peso das decisões permanentes e nos permitem pensar em outras coisas" (Juan, 2008, p. 444), e, prossegue Salvador Juan:

Apesar da aparente simpatia primordial que poderíamos ter pela ideia de espontaneidade e de uma vida algo aventureira, isto é, com imprevisibilidade, deve-se ter em conta que uma ausência absoluta de rotinas corresponderia a um autêntico "horror sociológico" e psicológico. (p. 443)

As rupturas da vida cotidiana no trabalho originam-se, pelo que se pode apreender das abordagens discutidas anteriormente, das variabilidades dos meios de trabalho, pela sua imprevisibilidade e pelas contradições entre os elementos do mundo real que devem ser articulados para que o trabalho aconteça.

O estudo do cotidiano de trabalho lança luz sobre os processos de dominação: se a atividade não é mera repetição de ordens, se a gestão não consegue chegar às entranhas do trabalho, há afinal algum espaço de resistência. Gardiner (2000) lembra-nos que o cotidiano é resistente porque escapa ao olhar da burocracia e dos controles. Esse é um aspecto importante e que aproxima as teorias que são objeto desta investigação:

Até certo ponto, o cotidiano tem essa qualidade resistente simplesmente porque a sua presença nem sempre é registrada pelo olhar panóptico do poder burocrático; ele continua a ser uma mistura incipiente e heterodoxa de práticas e de pensamentos fluidos, múltiplos e simbolicamente densos. (p. 15)

E não seria diferente com o cotidiano de trabalho: é lá que se esgotam as prescrições, contexto em que o planejado é replanejado, reunindo situações nas quais decisões entre possibilidades são tomadas diante dos elementos imediatamente presentes e dos valores que guiam as ações dos sujeitos.

O estudo do cotidiano se confunde nessas investigações com o estudo do trabalho real. O estudo do trabalho concreto opõe-se à teorização mais abstrata sobre o trabalho (no caso de alguns estudos psicossociais) ou aos estudos "à distância" via grandes conglomerados de dados secundários (no caso de um certo tipo de estudo sociológico, por exemplo).

Vale dizer que as ações que transcorrem nos cotidianos de trabalho têm que se haver com o mundo material dos meios de trabalho, o que faz lembrar que é de uma realidade sociotécnica que se está a tratar, na qual o imperativo da transformação da realidade (imperativo do real) e a consequente importância do ato estão presentes (Lhuilier, 2011).

Lhuilier (2011) desenvolve essa questão ao apontar os limites dos estudos sobre grupos em Kurt Lewin, na psicanálise e na psicossociologia para a compreensão das situações concretas de trabalho. Segundo a autora, em tais estudos:

Falta a referência à tarefa, à organização produtiva, à realidade que se trata de transformar nesses contextos. A história da dinâmica dos grupos, completamente absorvida pelas interações e, em seguida, pela investigação sobre a vida fantasmática, deixou na obscuridade a questão da ação. (p. 27)

Nessa linha é que a autora tece sua crítica aos estudos de Elton Mayo (1933) e à experiência de Hawthorne, qual seja, o esquecimento do sistema técnico, o que ela interpreta como uma ocultação do trabalho como transformação da realidade. Ao que ela contrapõe a teoria sócio-técnica (Trist, 1970) pelo seu valor em relacionar sistema técnico e sistema social.

A autora conclui sua análise das abordagens psicossociológicas do trabalho reafirmando a importância do estudo do trabalho como processo de enfrentamento com o real:

Mas a quantas anda a relação entre realidade psíquica e ação coletiva? Nessas diversas abordagens, que seguem essenciais para a análise clínica das relações sociais na organização, falta um aspecto central da função do fato organizacional e do vínculo social: as relações de re- 
ciprocidade ordenadas pela práxis, pelo imperativo de transformação da realidade. O trabalho e a reorganização do trabalho não são objetos privilegiados da teorização e da intervenção psicossociológica. (Lhuilier, 2011, p. 32)

\section{Considerações finais}

As contribuições mais importantes da antropologia, da ergologia e da psicologia social para o campo dos estudos sobre o trabalho são aquelas que colaboram para redefinirem o valor dos pequenos acontecimentos do dia a dia de trabalho, demonstrando como a análise dessas dimensões "microscópicas" pode lançar luz sobre o fenômeno do trabalho de modo geral. Assim, nossa análise situou o debate sobre o cotidiano de trabalho nessas três abordagens, discorrendo sobre suas contribuições para a compreensão e a transformação da vida no trabalho.

Embora enfatizem dimensões distintas das realidades que estudam, as três disciplinas reconhecem o valor dos saberes coletivamente construídos na atividade e lan- çam luz sobre as tensões micropolíticas que produzem o acontecer do trabalho.

O reconhecimento dos saberes práticos dos trabalhadores tem muitas implicações. Ele modifica a relação entre a ciência e seu objeto e lança desafios talvez incontornáveis à ideologia gerencial, isto é, revela-se um tipo de gestão feito pelos próprios trabalhadores e que, afinal, torna o trabalho possível.

Quanto às tensões micropolíticas, elas revelam-se, por exemplo, nas pequenas tentativas de reassumir o controle sobre o trabalho por meio dos processos de replanejamento ou renormatização (conceitos da psicologia social do trabalho e da ergologia, respectivamente) e das micronegociações que envolvem. Essas pequenas ações do dia a dia são guiadas por saberes construídos na relação com o trabalho e com outros trabalhadores e podem se revestir com um caráter de resistência.

Deve-se questionar, ainda, se as pequenas ações de resistência do cotidiano estabelecem relações com as ações coletivas mais visíveis, aspecto que mereceria ser mais aprofundado em estudos posteriores.

\title{
Psychosocial prospects for the study of daily life work
}

\begin{abstract}
This study aimed to analyze the debate and the theoretical and methodological deepening of studies on daily life work. The investigation started from the interdisciplinary dialogue among anthropology of work, ergology, and social psychology of work and it systematized the mutual contributions among these scientific fields, their approximations and their departures from the thematization and appropriation of human activity at work from the perspective of daily life. The comparative analysis highlighted axes which differentiate the ways for approaching the object, that refer to the relations established between practical and technical-scientific kinds of knowledge and the modes of intervening on work situations. Comparative approaches share the interest in knowing the real work, the value attributed to workers' knowledge and sensitivity to the micropolitical dimensions of daily life. One concludes that the location in each of these axes depends on the greater or lesser affiliation to the traditions of anthropology or ergonomics.
\end{abstract}

Keywords: Social psychology of work, ergology, anthropology of work, daily life, micropolitics.

\section{Perspectives psychosociales pour l'étude du quotidien de travail}

Resumé: Cette étude visait à analyser le débat et l'approfondissement théorique et méthodologique développé dans les études sur la vie quotidienne au travail. L'investigation a démarré à partir du dialogue interdisciplinaire entre l'anthropologie du travail, l'ergologie et la psychologie sociale du travail et il a systématisé les contributions mutuels entre ces domaines scientifiques, leurs approches et leurs départs de la thématisation et l'appropriation de l'activité humaine au travail sous la perspective du quotidien. L'analyse comparative a mis en évidence des axes qui différencient les manières pour approcher l'objet, qui se réfèrent aux relations établies entre savoirs pratiques et technico-scientifiques et aux manières d'intervention sur les situations de travail. Les approches comparatives partagent l'intérêt de connaître le vrai travail, la valeur attribuée à les savoirs des travailleurs et la sensibilité aux dimensions micropolitiques du quotidien. On en conclut que la localisation dans chacun de ces axes dépend d'une plus grande ou plus petite affiliation à les traditions d'anthropologie ou d'ergonomie.

Mots-clés: Psychologie sociale du travail, ergologie, anthropologie du travail, quotidien, micropolitique. 


\section{Perspectivas psicosociales para el estudio del cotidiano de trabajo}

Resumen: Este estudio tuvo como objetivo analizar el debate y la profundización teórica y metodológica desarrollada en los estudios acerca de la vida cotidiana en el trabajo. La investigación partió del diálogo interdisciplinario entre la antropología del trabajo, la ergología y la psicología social del trabajo y sistematizó las contribuciones mutuas entre eses campos científicos, sus aproximaciones y sus alejamientos de la tematización y la apropiación de la actividad humana en el trabajo bajo la perspectiva del cotidiano. El análisis comparativo destacó ejes que diferencian las formas de aproximación al objeto, que se refieren a las relaciones establecidas entre saberes prácticos y técnico-científicos y a los modos de intervención en las situaciones de trabajo. Los abordajes comparativos comparten el interés en conocer el trabajo real, el valor dado a los conocimientos de los trabajadores y la sensibilidad a las dimensiones micropolíticas del cotidiano. Se concluye que la localización en cada uno de eses ejes depende de la mayor o menor filiación a las tradiciones de la antropología o de la ergonomía.

Palabras clave: Psicología social del trabajo, ergología, antropología del trabajo, cotidiano, micropolítica.

\section{Referências}

Andrada, C. F. (2010). Etnografias em psicologia social: notas sobre uma aproximação fecunda. Ponto Urbe (Núcleo de Antropologia Urbana da USP), 7. Recuperado de http:// www.pontourbe.net/edicao7-cirkula/129-etnografiasem-psicologia-social-notas-sobre-uma-aproximacaofecunda\#_ftn1

Athayde, M., \& Brito, J. (2011). Ergologia e clínica do trabalho. In P. F. Bendassolli \& L. A. P. Soboll (Orgs.), Clínicas do trabalho: novas perspectivas para a compreensão do trabalho na atualidade (pp. 258-281). São Paulo, SP: Atlas.

Becker, H. S. (1999). Métodos de pesquisa em ciências sociais (4a ed.). São Paulo, SP: Hucitec.

Bouvier, P. (1989). Le travail au quotidien: une démarche socio-anthropologique. Paris: PUF.

Bouvier, P. (1990). El trabajo de todos los días: una aproximación socioantropológica al trabajo. Sociología del Trabalho: Revista Cuatrimestral de Empleo, Trabajo y Sociedad, 10, 131-139.

Bouvier, P. (1991). Socio-anthropologie du travail. Journal des Anthropologues, 43, 137-143.

Canguilhem, G. (1947). Milieu et normes de l'homme au travail. Cahiers Internationaux de Sociologie, 3, 120136.

Clot, Y. (2006). A função psicológica do trabalho. Petrópolis, RJ: Vozes.

Cutileiro, J. (1973). The anthropologist in his own society. Proceedings of the 10th Anual Conference of the Association of Social Anthropologists of Great Britain and Commonwealth. Oxford. (Manuscrito não publicado)

Daniellou, F. (Org.). (2004). A ergonomia em busca de seus princípios: debates epistemológicos. São Paulo, SP: Edgard Blücher.

Durão, S., \& Marques, E. M. (2001). Os vidreiros e a máquina, o tipógrafo e o designer: reflexões sobre antropologia do trabalho. Etnográfica, 5(1), 47-68.

Gardiner, M. E. (2000). Critiques of everyday life. Londres: Routledge.
Granjo, P. (1998). A antropologia e a abordagem da indústria e do risco: legitimidade e experiência de terreno. Etnográfica, 2(1), 73-89.

Granjo, P. (2004). Trabalhamos sobre um barril de pólvora: homens e perigo na refinaria de Sines. Lisboa: Imprensa de Ciências Sociais.

Guérin, F., Laville, A., Daniellou, F., Duraffourg, J., \& Kerguelen, A. (2001). Compreender o trabalho para transformá-lo: a prática da ergonomia. São Paulo, SP: Edgard Blücher.

Juan, S. (2008). Un enfoque socio-antropológico sobre la vida cotidiana: automatismos, rutinas y elecciones. Espacio Abierto Cuaderno Venezolano de Sociología, 17(3), 431-454.

Lefebvre, H. (1991). A vida cotidiana no mundo moderno. São Paulo, SP: Ática.

Leroi-Gourhan, A. (1945). Evolution et techniques (Vol. 2, Milieu et techniques). Paris: Albin Michel.

Lhuilier, D. (2006). Clinique du travail. Toulouse: Érès.

Lhuilier, D. (2011). Filiações teóricas das clínicas do trabalho. In P. F. Bendassolli \& L. A. P. Soboll (Orgs.), Clínicas do trabalho: novas perspectivas para a compreensão do trabalho na atualidade (pp. 22-58). São Paulo, SP: Atlas.

Magnani, J. G. C., \& Torres L. L. (Orgs.). (1996). Na metrópole: textos de antropologia urbana. São Paulo, SP: Edusp.

Marques, E. M. (2009). Um livro de Georges Friedmann e uma etnografia na fábrica: trabalho, máquinas e poder. In P. Godinho, S. P. Bastos \& I. Fonseca (Coords.), Jorge Crespo: estudos em homenagem (pp. 191-207). Lisboa: $100 \mathrm{Luz}$.

Mayo, E. (1933). The human problems of an industrial civilization. New York: Maemillan.

Oddone, I. (1984). La communauté scientifique élargie. Revue Société Française, 10, 28-33.

Oddone, I., Marri, G., Gloria, S., Briante, G., Chiatela, M., \& Re, A. (1986). Ambiente do trabalho: a luta dos trabalhadores pela saúde. São Paulo, SP: Hucitec. 
Oddone, I., Re, A., \& Briante, G. (1981). Redécouvrir l'expérience ouvrière: vers une autre psychologie $d u$ travail? Paris: Éditions Sociales.

Ombredane, A., \& Faverge, J. M. (1955). L'analyse $d u$ travail. Paris: PUF.

Rodrigues, A. M. (1999). Entrevista com Arakcy Martins Rodrigues. Cadernos de Psicologia Social do Trabalho, 2, 73-84.

Sato, L. (2010). Psicologia, saúde e trabalho: distintas construções dos objetos "trabalho" e "organizações". In Conselho Federal de Psicologia (Org.), Psicologia critica do trabalho na sociedade contemporânea. Brasília, DF: CFP.

Sato, L., Andrada, C. F., Évora, I. M. A., Neves, T. F. S., \& Oliveira, F. (2011). As tramas psicossociais da cooperação e da competição em diferentes contextos de trabalho. Arquivos Brasileiros de Psicologia, 63 (n. especial), 2-14.

Sato, L., Bernardo, M. H., \& Oliveira, F. (2008). Psicologia social do trabalho e cotidiano: a vivência de trabalhadores em diferentes contextos micropolíticos. Psicologia para América Latina, 15. Recuperado de http://psicolatina. org/15/cotidiano.html

Sato, L., \& Oliveira, F. (2008). Compreender a gestão a partir do cotidiano de trabalho. Aletheia, 27(1), 188-197.
Schwartz, Y. (2000a). A comunidade científica ampliada e o regime de produção de saberes. Trabalho e Educação, 7, 38-46.

Schwartz, Y. (2000b). Trabalho e uso de si. Pro-Posições, 1(5), 34-50.

Schwartz, Y. (2011). Conceituando o trabalho, o visível e o invisível. Trabalho, Educação e Saúde, 9(supl. 1), 19-45.

Schwartz, Y., \& Faïta, D. (1985). L'homme producteur. Paris: Éditions Sociales.

Silva, C. A. F. (2008). A gestão de si na reinvenção das normas: práticas e subjetividade no trabalho. Saúde \& Sociedade, 17(4), 111-123.

Spink, P. K. (1996). A organização como fenômeno psicossocial: notas para uma redefinição da psicologia do trabalho. Psicologia \& Sociedade, 8(1), 174-192.

Teiger, C. (1993). L'approche ergonomique: du travail humain à l'activité des hommes et des femmes au travail. Education Permanente, 3(116), 71-96.

Telles, A. L., \& Alvarez, D. (2004). Interfaces ergonomiaergologia: uma discussão sobre trabalho prescrito e normas antecedentes. In M. Figueiredo, M. Athayde, J. Brito \& D. Alvarez (Orgs.), Labirintos do trabalho: interrogações e olhares sobre o trabalho vivo. Rio de Janeiro, RJ: DP\&A.

Trist, E. L. (1970). A socio-technical critique of scientific management. London: Tavistock Institute. 